\title{
Atherosclerosis and Vascular Calcification in Chronic Renal Failure
}

\author{
V. Campean D. Neureiter I. Varga F. Runk A. Reiman C. Garlichs \\ S. Achenbach B. Nonnast-Daniel K. Amann
}

Departments of Pathology, Cardiac Surgery and Internal Medicine, Med. II and Med. IV, University of Erlangen-Nürnberg, Erlangen, Germany

\section{Key Words}

Atherosclerosis - Coronary artery sclerosis •

Chronic renal failure $\cdot$ Vascular calcification Plaque

calcification $\cdot$ Plaque morphology

\begin{abstract}
Cardiovascular complications are a major clinical problem in patients with chronic kidney disease and endstage renal failure; cardiac death accounts for approximately $40-50 \%$ of all deaths in these patients. Death from cardiovascular causes is up to 20 times more common in uremic patients than in the general population with the risk being even higher than in patients with diabetes mellitus. A high rate of myocardial infarction and excessive cardiac mortality have repeatedly been documented in patients with kidney disease and renal failure. Not only is the prevalence of myocardial infarction high, but also the case fatality rate is significantly higher in uremic patients with and without diabetes, respectively, compared to nonuremic patients. This is of particular interest since the prevalence of coronary atheroma in uremic patients was shown to be approximately $30 \%$ by autopsy and coronary angiography studies. Thus, coronary factors, i.e. atherosclerosis, and non-coronary factors may play an important role in the genesis of cardiac complications in the renal patient. In addition, renal failure recently has also be identified as a predictor of mortality in different stages of peripheral vascular disease. In particular,
\end{abstract}

marked differences in the pathogenesis, morphology and course of atherosclerosis and arteriosclerosis under the conditions of renal failure have been documented. Among others increased plaque formation and particularly higher proportion and intensity of vascular calcification have been found in clinical and autopsy studies. In addition to the so-called classical or traditional risk factors, an important role for nonclassical risk factors such as microinflammation, hyperphosphatemia and oxidative stress has been documented in patients with renal failure and is discussed in detail.

Copyright $\subset 2005$ S. Karger AG, Basel

\section{Introduction}

The initial enthusiasm for dialysis as a survival measure for patients with chronic kidney disease was tempered in 1974, when Lindner et al. [1974] noted the extraordinarily high frequency of coronary heart disease and cardiac death of the first patients, who underwent dialysis in Seattle at that time. This observation led to the hypothesis of accelerated atherosclerosis in chronic renal failure, which has remained disputed until today. For a long time, however, it was unclear whether or not this observation is fully explained by the high prevalence of classical cardiovascular risk factors in uremia or whether pathogenetic factors which are specific for renal dysfunction accelerate atherogenesis in uremia - and, as we know

\section{KARGER}

Fax +4161306 1234

E-Mail karger@karger.ch

www.karger.com
(C) 2005 S. Karger AG, Basel

1420-4096/05/0286-0280\$22.00/0

Accessible online at:

www.karger.com $/ \mathrm{kbr}$
Prof. Dr. Kerstin Amann

Department of Pathology, University of Erlangen-Nürnberg

Krankenhausstrasse 8-10, DE-91054 Erlangen (Germany)

Tel. +49 9131852 2291, Fax +49 91318522601

E-Mail kerstin.amann@patho.imed.uni-erlangen.de 
today, even in states of minor renal dysfunction. There is now, however, an increasing body of experimental and clinical evidence that (1) atherosclerosis is advanced in renal failure, i.e. atherosclerotic lesions develop early on in the course of renal dysfunction and show increased size, and (2) there are indeed some specific morphological findings in arteriosclerosis, i.e. thickening of the vascular wall of peripheral arteries, and atherosclerosis, i.e. plaque formation in elastic type arteries, under the condition of renal failure. In particular, the prevalence and intensity of vascular calcification are increased in patients with renal failure and this is in part due to enhanced calcification of the arterial media, but also to increased calcification of atherosclerotic plaques.

In addition to renal failure being a risk factor for increased mortality after myocardial infarction and congestive heart failure, recent clinical studies also provided evidence for an increased incidence rate of peripheral artery disease in patients with chronic renal disease [Leskinen et al., 2002; O'Hare et al., 2002; Hosokawa et al., 2005]. O'Hare et al. [2005] showed that both moderate and severe renal insufficiency are associated with an increased odds of death in patients with critical limb ischemia.

Against this background it is the aim of the following review to address some of these aspects with particular emphasis on the morphology and potential pathomechanisms of advanced coronary and peripheral atherosclerosis and vascular calcification in renal failure.

\section{Accelerated Atherosclerosis in Chronic Renal Failure? - Data from Clinical and Experimental Studies}

The high prevalence of atherosclerotic lesions in patients with chronic renal failure has been documented in clinical registers and numerous autopsy studies [US Renal Data System, 1995; Amann and Ritz, 2001; Clyne et al., 1986]. The high occurrence of coronary incidents has also been shown in a number of retrospective and prospective studies [Ansari et al., 1993; Ikram et al., 1983; Kramer et al., 1986; Harnett et al., 1996]. Epidemiological data document an excessive rate of coronary events in patients with renal dysfunction. Furthermore, studies using electron beam computer tomography (EBCT) have shown accelerated deposition of calcium even in the coronaries of patients whose renal function was only slightly impaired [Raggi et al., 2002] indicating that these alterations occur very early on in the course of renal disease. In patients with end-stage renal disease who had come to autopsy staging of coronary plaques according to Stary documented more frequent calcification of coronary plaques [Schwarz et al., 2000].

However, all these studies have not resolved the question as to whether atherogenesis progresses with acceleration in patients with renal failure or if the high prevalence can be explained simply by the large number of risk factors that are present in these patients. There are interesting new findings for a rapid appearance of an advanced coronary arterial sclerosis in young adults having chronic renal failure since childhood [Oh et al., 2002]. In addition, several clinical and autopsy studies have documented a high incidence of plaque and medial calcifications in patients with renal failure [Schwarz et al., 2000; Moe et al., 2002].

Since the issue of advanced atherosclerosis and in particular the mechanisms of vascular calcification is difficult to investigate in patients with end-stage disease, we and others have been searching for a suitable experimental model to examine the pathogenesis and extent of atherosclerosis in chronic renal failure. Most animal species do not develop spontaneous atherosclerosis comparable to the human situation. This is also true for the subtotally nephrectomized or 5/6 nephrectomized rat which is most widely used for studies in renal disease. Very seldom calcification of the aorta can be found in these subtotally nephrectomized animals with long-term renal failure (fig. 1). Of note, medial calcification in these animals predominantly occurs at the site of elastic fiber disruption which is a typical early event in rats with renal failure [Amann et al., 1995].

Until recently the most widely used animal model has been the rabbit model with high cholesterol diet. A previous study by a Danish group [Tvedegaard and Kamstrup, 1980] found that rabbits with renal failure developed atherosclerotic plaques in the aorta. The rabbit, however, is a difficult laboratory animal and requires high cholesterol feeding. A better model would be, however, a model of spontaneous atherosclerosis without dietetic manipulations. Recently, such a model has been described in the form of the Apo E lipoprotein knockout mouse (ApoE-/-), which spontaneously develops atherosclerosis in the aorta and in the large arteries. This model has been used by several research groups to determine vascular changes caused by uremia [Buzello et al., 2003; Muntzel et al., 2002; Bro et al., 2003, 2004] and to study other mechanisms relevant for atherosclerosis [Amann et al., 2004]. Induction of chronic renal failure by subtotal nephrectomy, i.e. $5 / 6$ nephrectomy, in these animals produces larger atherosclerotic plaques. This finding suggests 

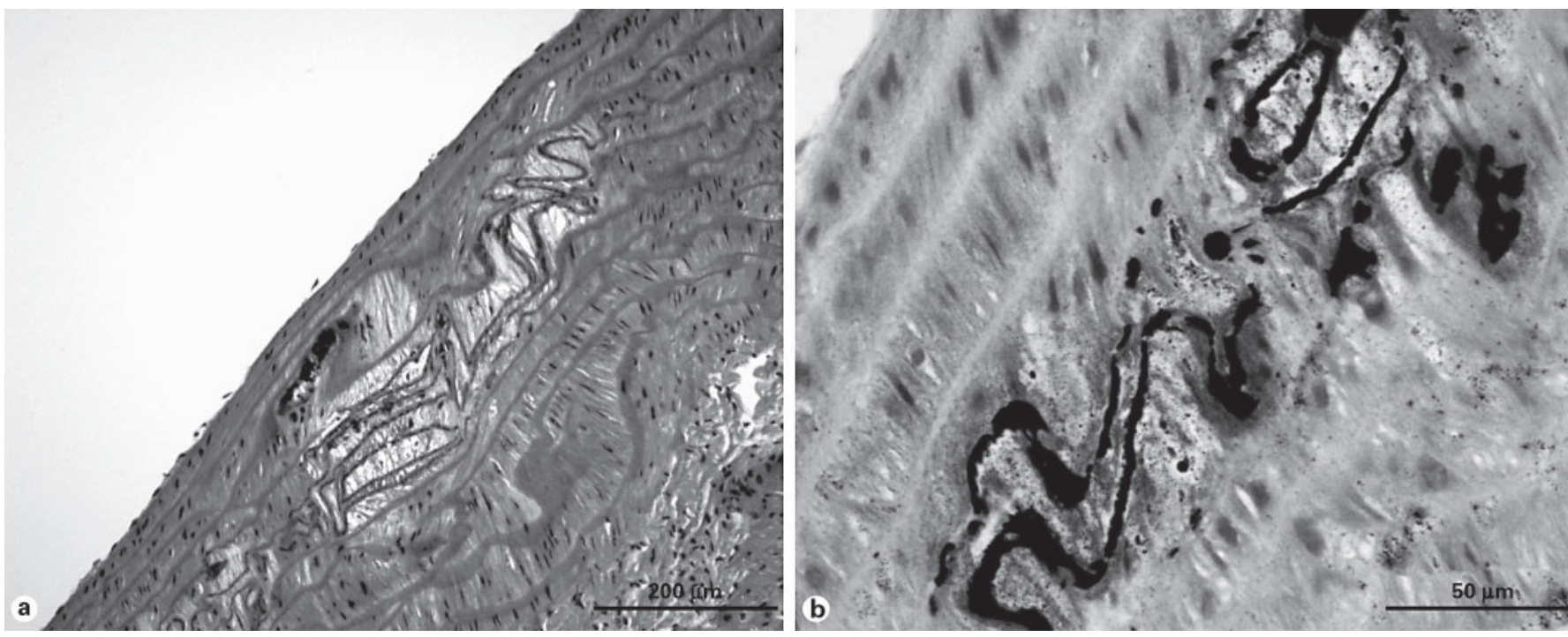

Fig. 1. Calcification of the aortic root at sites of elastic fiber disruption in a subtotally nephrectomized rat with chronic renal failure. a HE stain documenting rupture and disarray of elastic fibers. b Van Kossa stain documenting calcification along the ruptured elastic fibers.

that renal failure rather than producing a de novo increase of atherosclerotic plaques causes the growth of the existing plaques to be speeded up and thus causing larger lesions. The initial plaques, arising after short-term moderate renal failure, contain macrophages, loaded with lipid but have only very few inflammation cells. They show a positive staining for several markers of inflammation and increased oxidative stress, i.e. early activation of the CD40-CD154 ligand system that has been shown to be of importance in the early steps of inflammation, increased expression of the adhesion molecules ICAM and VCAM, nitrotyrosin (as a marker for oxidative stress), RAGE, the receptor for advanced glycation end products (AGE), as a proof of endothelial cell activation, PCNA (proliferating cellular nuclear antigen), a marker of cell proliferation, as well as staining for osteopontin, collagen IV and several other factors [Bro et al., 2004; Amann et al., 2004; Park et al., 1998]. Recently, Ivanovski and coworkers showed that antioxidative treatment with $\mathrm{N}$-acetylcysteine prevented accelerated atherosclerosis in uremic APOE-/- mice [Ivanovski et al., 2005].

Another animal model that was recently used for analysis of plaque formation under the conditions of renal failure is the LDL receptor knockout mouse [Davies et al., 2003]. Using this animal model which also requires a high cholesterol diet Davies et al. [2003] confirmed that uremia increases plaque size and vascular calcification. Interestingly, plaque formation and calcification could be completely prevented by treatment of the uremic animals with BMP-7 (bone morphogenous protein-7). Although the mechanism underlying the beneficial effect of BMP-7 in this animal model is yet unknown, these findings are of interest since BMP-7 is already available for clinical use in patients with renal failure.

Thus, it can be concluded from the above-mentioned clinical and experimental investigations that atherosclerotic plaques really grow more rapidly in an uremic milieu, i.e. larger lesions are formed, and that this process starts very early on in the context of renal disease.

\section{Role of Oxidative Stress in the Initiation of Atherosclerosis in Renal Failure}

Oxidative stress, i.e. the accumulation of highly reactive oxygen radicals like oxygen superoxide, hydro-oxyradicals, hydroxyperoxide or peroxynitrate, can be initiated by a number of different mechanisms. Reactive oxygen radicals (ROS) are not necessarily only pathogenic. They represent, for example, important physiological signal molecules that transmit the effect of agonists like angiotensin II (AngII). AngII stimulates the ROS generating NADP $(\mathrm{H})$ oxidase and triggers a signal cascade by src kinase, MEK and MAP kinase [Touyz and Schiffrin, 2001]. In contrast, a neutralization of the ROS prevents the rise in blood pressure and vascular impairment after 
administration of AngII, which evidently leads to a ROS surplus. ROS interact with nitric oxide (NO) that leads to formation of the very potent molecule peroxynitrate. Since AngII is found in the plaques together with inflammatory cytokines like IL-6 [Schieffer et al., 2000], it is reasonable to use ACE-inhibitor as in the HOPE study [Yusuf et al., 2000] or Ang II receptor blocker as in the LIFE study [Dahlof et al., 2002] to reduce the cardiovascular risk. Evidence for increased oxidative stress was also found in the above-mentioned animal experiments in ApoE-/- mice after induction of moderate renal dysfunction (by uninephrectomy) or renal failure (by subtotal nephrectomy), respectively.

Against this background it may be interesting to summarize which reactions are induced by the formation of ROS [Touyz, 2005]: The synthesis of ROS is regulated by a number of different enzymes such as the xanthine-oxidase in peroxysomes, an increased or uncoupled mitochondrial oxidation, the NAD $(\mathrm{P}) \mathrm{H}$ oxidase, the endothelial NO synthase in its released state (for instance, if the availability of active biotin is reduced) and the lipo-oxygenase or myeloperoxidase. The ROS formation is enhanced nonenzymatically by transition metals, especially by iron. In contrast, there are numerous mechanisms that protect against oxygen toxicity, among them are enzymatic (like the superoxidedismutase or the catalase) trace element catchers, like transferrin, ferritin and lactoferrin, and above all nonenzymatic substances like glutathionine or melatonin, especially important from a therapeutic point of view, vitamin E, vitamin $\mathrm{C}$. The therapeutic importance of vitamin $\mathrm{E}$ is still very controversial despite recently published reports showing a positive effect on cardiovascular outcome in a small number of uremic patients [Boaz et al., 2000]. This could possibly be due to the very different antioxidative potential of the different isoforms of vitamin E (tocopherol). Nevertheless, in a recent experimental study in rats with renal failure the administration of high doses of $\alpha$-tocopherol could prevent morphological cardiac changes, i.e. the interstitial myocardial fibrosis, the wall thickening of myocardial arteries and the lessening of capillary supply [Amann et al., 2002].

As a result we conclude that a ROS surplus always results when an imbalance exists between the formation of ROS and the antioxidative mechanisms. At the moment it appears that both mechanisms contribute to the increase in oxidative stress in chronic renal failure. One of the reasons for the reduced antioxidative capacity in renal failure may be the reduced number of erythrocytes, which are highly effective mobile ROS scavengers [Siems et al., 2000].

Atherosclerosis and Vascular Calcification in Chronic Renal Failure
Oxidative stress has numerous undesirable side effects, which are relevant to atherogenesis. Serum levels of cytotoxic aldehydic lipid peroxidation products such as 4-hydroxynonenal and malondialdehyde, of homocysteine, of cholesterol oxidation products (i.e. 7-ketocholesterol, cholesterol-epoxides), and of isoprostanes - the level of which strongly correlate with the parameters of inflammation - are increased in patients with chronic renal failure [Siems et al., 2002]. A further example is the induction of the central inflammation modulator nuclear factor kappa-B (NF-kappa-B) by ROS. Under normal conditions the proinflammatory central switch of the inhibitor I-kappa-B is blocked. Oxygen radicals abolish this inhibition thus leading to a translocation of the 50- and 65-kDa stimulatory peptides in the nucleus and induction of the genetic programs, which switch on a local and systematic inflammatory reaction. This raises the question of whether such an inflammatory reaction is observed in chronic renal failure and whether there is increasing evidence that this is indeed the case: Witko-Sarsat et al. [1998] investigated patients in early stages of chronic renal failure and discovered increased plasma concentration of C-reactive protein (CRP), IL-6, advanced oxidation protein products (AOPP), IL-1 receptor antagonists and soluble TNF receptors, whose concentration increased with increasing plasma creatinine. Based on these data it is evident that uremia per se is a proinflammatory state. In chronic renal failure the development of microinflammation occurs irrespective of dialysis per se, but is aggravated by it [Stenvinkel et al., 1999]. Recently published studies show that the CRP concentrations, determined using highly sensitive assays, is a predictor for allcause mortality and specifically for cardiovascular mortality, not only in the general population [Ridker et al., 2000], but especially in renal failure patients [Zimmermann et al., 1999]. The trigger for such local inflammatory reactions is unknown. Recent experimental studies documented a direct pro-atherogenic and pro-inflammatory role of CRP [Schwedler et al., 2005] thus excluding the hypothesis that the increase in CRP is just a side effect. In addition, it has been shown that fetuin-A, an important inhibitor of calcification that is reduced in patients with renal failure, may have also anti-inflammatory properties and is negatively correlated to CRP levels in patients with renal failure [Ketteler et al., 2005; Moe and Chen, 2005; Moe et al., 2005].

Recently the hypothesis of a role of the terminal component of complement system, i.e. C5b-9, in atherosclerosis in uremia has been advanced [Deppisch et al., 2001]. Complement is deposited in the atherosclerotic plaque 
together with C-reactive protein (CRP). Those common deposits of complement and CRP are a known feature of non-renal patients with coronary heart disease [Torzewski et al., 1998] and may suggest a combination of both factors in tissue damage, although no clear evidence exists up to now.

Another factor of the complement system which had up to now only little attention is complement factor D of the alternative complement pathway [Deppisch et al., 2001]. This factor is a low-molecular-weight protein and cumulates in renal failure. Factor D is activated by enzymes and cleaves continuously complement factor B, through which the alternative activation path of the complement system is activated. This causes very high rates of complement activation, also achieves an intensified formation of the end product of complement activation (the so-called membrane attack complex C5b9), particularly if the system sees activating signals, such as bio-incompatible membranes. In other words, the complement system of renal failure patients produces thus higher concentrations of complement products and thereby an increased complement-mediated damaging. This is interesting because very high concentrations of complement factors are found in the so-called soft plaques. Whereas low concentrations of the activated complement bring about an activation of the cell, high concentrations lead to cellular necrosis, also relevant for macrophages in atherosclerotic plaques.

\section{Are There Differences between the Coronary Plaques of Patients with and Patients without Kidney Disease?}

Evidently, the frequency of coronary atherosclerotic plaques in patients with chronic kidney disease is increased, but do differences exist between the plaque morphology of uremic and healthy patients? As mentioned above, Schwarz et al. [2000] found conspicuous differences in the plaque morphology of uremic patients and controls with coronary arteriosclerosis. The plaque morphology was classified according to the widely used Stary's classification [Stary et al., 1995] that categorizes atherosclerotic plaques in different types of lesions from type I, the initial atherosclerotic lesion, to type VII, the complicated atherosclerotic plaque. Using this approach clearly more advanced stages of atherosclerosis were found in renal failure patients, although it should be noted that above all the type VII lesion, i.e. the calcified atherosclerotic plaque (fig. 2), was significantly more frequent in renal failure patients than in healthy kidney controls. A simplified explanation would be that calcified plaques represent unproblematic lesions, which are in fact desirable. In the past it was thought that calcified plaques are more quiescent than noncalcified ones [Boyle et al., 2005]. It is well known that not those plaques, which cause an advanced vascular stenosis, cause the death of a patient, but the nonstenosing, soft and very inflammatory altered plaque. This idea presumably has to be revised, since calcified deposits were documented in most patients suffering from coronary thrombosis due to plaque rupture [Huang et al., 2001]. In addition, it was shown that calcification did not impact on biomechanical stress in human atherosclerotic lesions, since removal of calcium did not significantly change stress [Huang et al., 2001]. However, a study on compressive stress-relaxation found marked differences of stress relaxation between calcified plaques and non-calcified ones [Schmermund et al., 2001]. Thus, it is very well possible that calcified plaques increase the risk of plaque rupture by imposing abnormal stress on the shoulder, i.e. the transition between calcified plaque and intact endothelium.

X-ray diffraction analysis of the coronary plaques revealed deposits of hydroxyapatite crystals in the plaques of uremic patients [Schwarz et al., 2000]. In addition, smaller crystalline granules were found in the plaques, but not consistently in the vascular media. This finding differs apparently from the findings in muscular arteries, where well-formed media calcification is seen [Moe et al., 2002] indicating that apart from increased plaque calcification in the aorta and coronary arteries there is also increased calcification of the smaller elastic and media of muscular-type arteries [London et al., 2004; Ketteler et al., 2005]. When Moe and coworkers [2002] investigated the A. epigastrica inferior in patients with renal disease at the time of transplantation, they found medial calcification in about $46 \%$. Using immunohistochemistry, they could point out similarities between bone formation and medial calcification in patients with renal failure. There seems to be a tendency to more rapid and more sever calcification of the vasculature in general under the conditions of renal failure since heavy calcification of peripheral veins can also be found in these patients (fig. 3 ).

This discrepancy between intimal calcification in coronary arteries on the one hand and medial calcification in the aorta and peripheral arteries on the other points to the enormous heterogeneity between different vascular regions. Therefore, it is impossible to draw any conclusions pertaining to the changes in the coronary arteries on the basis of findings in the A. radialis. This im- 
Fig. 2. Calcified coronary atherosclerotic plaque of a patient with chronic renal failure.

Fig. 3. Heavy calcification of a peripheral vein of a patient with chronic renal failure.
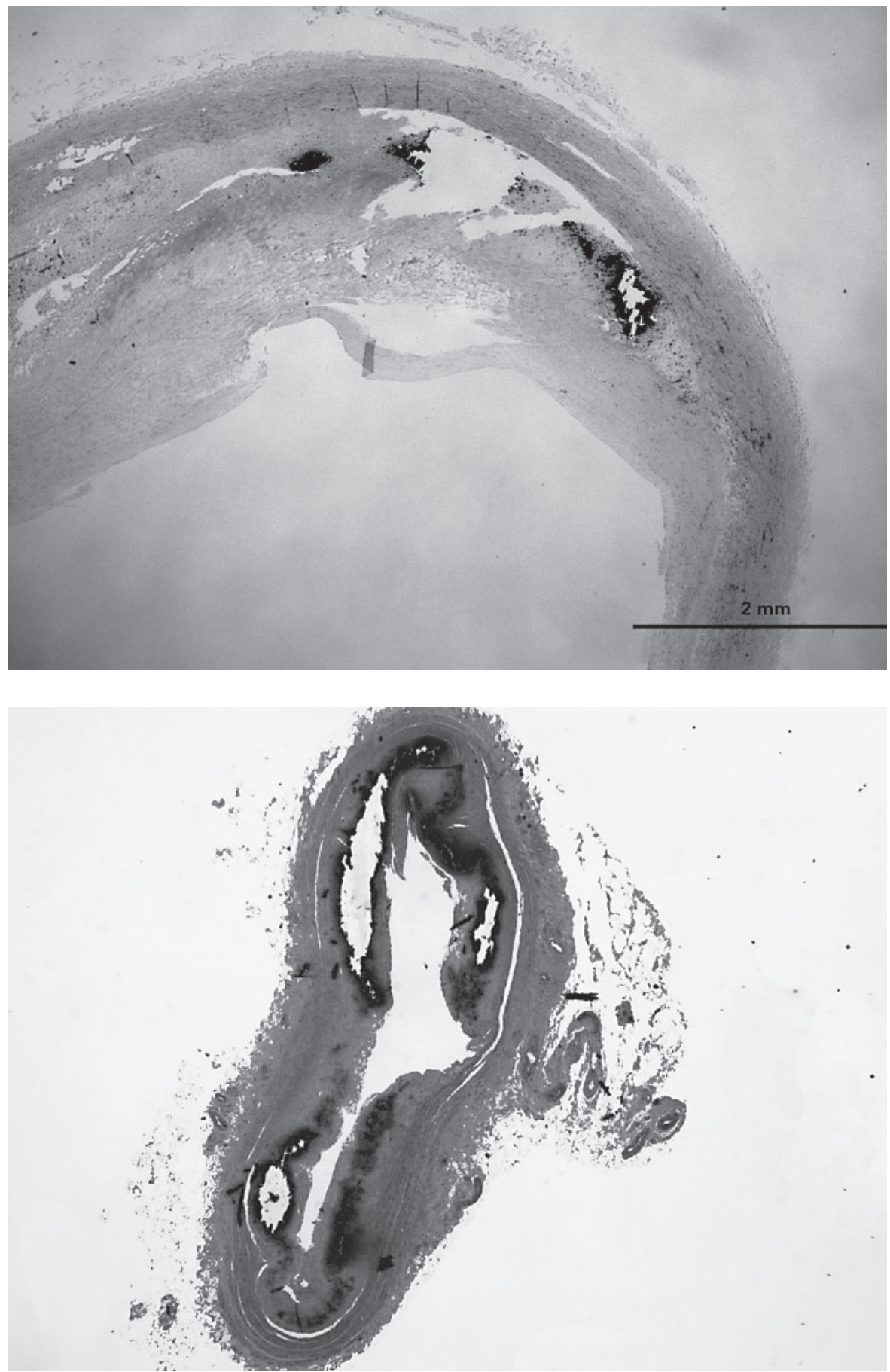

portant aspect, however, requires further experimental and clinical studies.

It is well known that plaque rupture may be finally caused by angiogenesis in the adventitia of the coronary arteries leading to an intramural hematoma formation and rupture of the fibrous cap [Richardson et al., 1989].
Presently, current investigations are focusing on the question of whether this process progresses more rapidly in uremia. Up to now there is no definite answer.

The transition area between the plaque and the surrounding vessel can for instance rupture, if a paradox vasoconstriction occurs. Atherosclerotic vascular seg- 
ments are either lacking endothelial substance or are covered with a dysfunctional endothelium and to that extent are predestined to a paradox vasoconstriction.

In addition, uremic patients show an increased sympathetic tone and the levels of catecholamine concentrations during dialysis sessions are only found in pheochromocytoma. The paradox and catecholamine-mediated vasoconstriction could thus contribute to plaque rupture and favor the malignant character of calcified plaques present in chronic renal failure.

It still cannot be stated that calcified plaques are simply an indicator of a high plaque burden, which includes calcified as well as uncalcified, so-called soft and rupture endangered plaques. This can be finally resolved only through further investigation. The introduction of electron beam computed tomography (EBCT) with quick data acquisition has enabled the discovery of coronary calcification on the beating heart as a result. Following the first description of such changes using EBCT [Braun et al., 1996], Goodman et al. [2000] demonstrated a high frequency and a rapid progress of coronary calcifications in young dialysis patients. However, it is still unclear if the presence of calcified coronary plaques possesses a similarly high predictive value for cardiac events in coronary patients as in the general population [Goodman et al., 2004].

London and coworkers [2003, 2004] investigated the possible mechanisms responsible for increased arterial calcification in renal failure with particular emphasis on disturbances of mineral metabolism and active expression of various mineral-regulating proteins. This is of interest since an inverse relationship between arteriosclerosis and bone density has been documented in uremic patients. In their study, the authors found that a high arteriosclerosis score was associated with bone histomorphometry suggestive of low bone activity and adynamic bone disease. These results suggest that therapeutic interventions associated with excessive lowering of parathyroid activity (parathyroidectomy, excessive calcium or aluminum load) favor lower bone turnover and adynamic bone disease, which could influence the development and progression of arteriosclerosis.

\section{Possible Role of Hyperphosphatemia for Accelerated Calcification in Renal Failure?}

In the experimental model of subtotal or $5 / 6$ nephrectomy, we [Amann et al., 2003] and others [Neves et al., 2004] could document an effect of high phosphorus diet on myocardial hypertrophy, interstitial fibrosis and vascular hypertrophy under the conditions of renal failure. Interestingly, these effects were not corrected by PTH replacement suggesting an PTH-independent effect of hyperphosphatemia [Neves et al., 2004]. The group of Slatopolsky [Cozzolino et al., 2003] documented heavy vascular and soft tissue calcification in subtotally nephrectomized rats that were given a high phosphorus diet $(0.9 \%$ $\mathrm{P}, 0.6 \% \mathrm{Ca}, 20 \%$ protein) for 6 months. Interestingly, these calcifications could be completely prevented by the Ca-free phosphate binder sevelamer whereas phosphate binding with $3 \% \mathrm{CaCO}_{3}$ had not effect. These experimental results provide further arguments for a role of phosphorus in concert with high $\mathrm{Ca}$ concentrations in the pathogenesis of vascular and soft tissue calcifications in renal failure. Of note, recent clinical studies using EBCT documented a beneficial effect of calcium free phosphate binders on progression of arterial calcification [Chertow et al., 2003; Huybrechts et al., 2005].

The group of Giachelli showed that in vitro exposure of smooth vascular muscle cells (VSMC) to high phosphate concentrations leads to a change in the phenotype of the cells [Jono et al., 2000]. In this context, osteoblastspecific genetic programs are initiated with expression of osteopontin, bone morphogenetic protein (BMP), isoforms, osteocalcin, Cbfa-1, etc. [Demer et al., 2002]. This rearrangement is accompanied by a deposit of membrane-bound hydroxyapatite granula, very similar to the changes in coronary plaques [Schwarz et al., 2000]. This observation is important in view of recent clinical findings [Block et al., 1998; Ganesh et al., 2001] documenting that in dialysis patients a predialytic serum phosphate concentration of more than $6.5 \mathrm{mg} / \mathrm{dl}$ raises the all-cause mortality and specifically the risk of cardiac death. Of note, serum calcium concentrations were not significantly associated with higher cardiovascular risk. This effect of hyperphosphatemia is not limited only to renal disease patients. Narang et al. [1997] found that also in nonrenal patients with coronary heart disease the serum phosphate concentration represented a potent predictor of the severity of vascular constriction. This observation suggests a more general role of serum phosphate in the development of coronary plaques.

Of note, when Boaz et al. [2005] investigated the role of $\mathrm{P}$ and $\mathrm{Ca} \times \mathrm{P}$ as risk factors for incident peripheral vascular disease (PVD) in HD patients with pre-existing cardiovascular disease and performed a multivariate analysis, they could show that serum $P$ remained the only significant predictor of incident PVD. 
In addition to plaque formation and calcification, a significant thickening of the vascular wall of coronaries was found with unchanged vascular lumen, a fact that points to a so-called concentric remodeling of the coronary arteries [Amann et al., 2001]. Using ultrasound of the carotid artery this marked increase in intima-media thickness, i.e. arteriosclerosis of muscular type arteries, was recently also confirmed in predialytic and dialytic patients with renal disease by a large clinical studies [Shoji et al., 2002].

Of note, a recent study by Pannier et al. [2005] provided evidence that, in ESRD, increased stiffness of capacitive arteries, like the aorta, is an independent strong predictor of cardiovascular mortality, whereas stiffness of peripheral conduit arteries had no prognostic value.

\section{Cardiovascular Risk of the Predialytic Patient}

Given the data on the more aggressive course of atherosclerosis in renal failure the important question arises at which point in the development of renal disease does an increase in coronary risk occur? The answer is: very early, at a time, in which the glomerular filtration rate (GFR) may be still normal, which certainly does not necessarily exclude that a clear loss of functionable nephron has already occurred. This is documented in recent animals experiments where only a very mild disturbance of renal function by uninephrectomy could increase plaque formation and oxidative stress [Buzello et al., 2003]. In patients with biopsy-proven IgA glomerulonephritis, Stefanski et al. [1996] showed a significant increase in left ventricular wall thickness as well as signs of cardiac dysfunction despite normal blood pressure and S-creatinine values in patients with incipient renal disease. Fliser et al. [1998] found a significant insulin resistance already at a GFR of $80 \mathrm{ml} / \mathrm{min}$. Kronenberg et al. [2000, 2002] showed that proteinuric patients with kidney disease had an increased $\mathrm{Lp}(\mathrm{a})$ and apolipoprotein A-IV concentration despite normal inulin clearance. Other investigators have shown an early increase of homocystine concentration [Jungers et al., 1999]. Of special interest in this regard is the recent observation of Kielstein et al. [2002], who found increased concentration of asymmetric dimethyl$L$-arginine (ADMA), an inhibitor of NO-synthase, in patients, whose inulin clearance was still normal. ADMAlevels are significantly correlated to cardiac mortality in the general population [Valkonen et al., 2001] and in dialysis patients [Zoccali et al., 2002]. ADMA is associated with intima thickness of the A. carotis [Zoccali et al., 2002] and possibly even to coronary events [Brzosko et al., 2002]. In addition to ADMA accumulation due to impaired renal excretion under the conditions of renal failure, dysregulation of the enzyme dimethylarginine dimethylaminohydrolase (DDAH) with consecutive increase in plasma ADMA concentration and chronic NOS inhibition is a common pathophysiological pathway in numerous clinical conditions. In addition, recent in vitro work documented that recombinant erythropoietin increases asymmetric dimethylarginine in endothelial cells [Scalera et al., 2005]. Recent work of DescampsLatscha et al. [2005] documented that CRP, fibrinogen, and AOPP levels independently predict atherosclerotic cardiovascular events in patients with chronic kidney disease even in the predialysis phase and might thus directly contribute to the uremia-associated accelerated atherogenesis.

\section{Conclusions}

The extent of atherosclerosis is undoubtedly high in patients with chronic renal failure and the consequences, i.e. cardiovascular events, represent a major clinical problem in these patients. Experimental findings now confirm an acceleration of atherosclerosis under the conditions of renal failure as well as early upregulation of markers of inflammation and oxidative stress. The process begins apparently very early in the development of chronic renal failure and is accompanied by endothelial dysfunction and increased oxidative stress. In the following, the course of the disease is characterized by a more severe calcification of plaques and the arterial media. Increased knowledge about the pathogenesis of early and late atherosclerotic lesions in renal failure may open the possibility for prevention of lesion formation and adequate treatment thus representing further arguments for the early examination of kidney disease patients by a nephrologist. In addition to the well-described traditional risk factors, new uremic-specific, nonclassic risk factors have been identified such as microinflammation, hyperphosphatemia and oxidative stress whose treatment includes potentially important clinical implications.

\section{Acknowledgement}

The work was supported by the Interdisciplinary Centre for Clinical Research (IZKF) at the University Hospital of the University of Erlangen-Nürnberg; Project No. B40/A11. 


\section{References}

Amann K, Gross ML, Ritz E: Pathophysiology underlying accelerated atherogenesis in renal disease: closing in on the target. J Am Soc Nephrol 2004;15:1664-1666.

Amann K, Miltenberger-Miltenyi G, Simonaviciene A, Koch A, SR Orth, Ritz E: Remodeling of resistance arteries in renal failure: effect of endothelin receptor blockade. J Am Soc Nephrol 2001;12:2040-2050.

Amann K, Neususs R, Ritz E, Irzyniec T, Wiest G, Mall G: Changes of vascular architecture independent of blood pressure in experimental uremia. Am J Hypertens 1995;8:409-417.

Amann K, Ritz E: The heart in renal failure - a specific uremic cardiomyopathy? J Clin Bas Cardiol 2001;4:109-113.

Amann K, Törnig J, Buzello M, et al: Effect of antioxidant therapy with dl-alpha-tocopherol on cardiovascular structure in experimental renal failure. Kidney Int 2002;62:877-884.

Amann K, Törnig J, Kugel B, Gross ML, Tyralla K, El-Shakmak A, Szabo A, Ritz E: Hyperphosphatemia aggravates cardiac fibrosis and microvascular disease in experimental uremia. Kidney Int 2003;63:1296-1301.

Ansari A, Kaupke CJ, Vaziri ND, Miller R, Barbari A: Cardiac pathology in patients with endstage renal disease maintained on hemodialysis. Int J Artif Organs 1993;16:31-36.

Block GA, Hulbert-Shearon TE, Levin NW, Port FK: Association of serum phosphorus and calcium $\times$ phosphate product with mortality risk in chronic hemodialysis patients: a national study. Am J Kidney Dis 1998;31:607-617.

Boaz M, Smetana S, Weinstein T, et al: Secondary prevention with antioxidants of cardiovascular disease in end-stage renal disease (SPACE): randomised placebo-controlled trial. Lancet 2000;356:1213-1218.

Boaz M, Weinstein T, Matas Z, Green, Smetana S: Peripheral vascular disease and serum phosphorus in hemodialysis: a nested case-control study. Clin Nephrol 2005;63:98-105.

Boyle JJ: Macrophage activation in atherosclerosis: pathogenesis and pharmacology of plaque rupture. Curr Vasc Pharmacol 2005;3:63-68.

Braun J, Oldendorf M, Moshage W, Heidler R, Zeitler E, Luft FC: Electron beam computed tomography in the evaluation of cardiac calcification in chronic dialysis patients. Am J Kidney Dis 1996;27:394-401.

Bro S, Bentzon JF, Falk E, Andersen CB, Olgaard K, Nielsen LB: Chronic renal failure accelerates atherogenesis in apolipoprotein E-deficient mice. J Am Soc Nephrol 2003;14:2466-2474.

Bro S, Moeller F, Andersen CB, Olgaard K, Nielsen LB: Increased expression of adhesion molecules in uremic atherosclerosis in apolipoprotein-E-deficient mice. J Am Soc Nephrol 2004; 15:1495-1503.

Brzosko S, Krauze-Brzosko K, de Gaetano G, Iacoviello L: Asymmetrical dimethylarginine and risk of acute coronary events. Lancet 2002;359:1620.
Buzello M, Törnig J, Faulhaber J, Ehmke H, Ritz E, Amann K: The (apo) E knockout mouse - a model documenting accelerated atherosclerosis in uremia. J Am Soc Nephrol 2003; 14:311316.

Chertow GM, Raggi P, McCarthy JT, Schulman G, Silberzweig J, Kuhlik A, Goodman WG, Boulay A, Burke SK, Toto RD: The effects of sevelamer and calcium acetate on proxies of atherosclerotic and arteriosclerotic vascular disease in hemodialysis patients. Am J Nephrol 2003;23:307-314.

Clyne N, Lins LE, Pehrsson SK: Occurrence and significance of heart disease in uraemia. Scand J Urol Nephrol 1986;20:307-311.

Cozzolino M, Staniforth ME, Liapis H, Finch J, Burke SK, Dusso AS, Slatopolsky E: Sevelamer hydrochloride attenuates kidney and cardiovascular calcifications in long-term experimental uremia. Kidney Int 2003;64: 1653-1661.

Dahlof B, Devereux RB, Kjeldsen SE, et al: Cardiovascular morbidity and mortality in the Losartan Intervention For Endpoint reduction in hypertension study (LIFE): a randomised trial against atenolol. Lancet 2002;359:9951003.

Davies MR, Lund RJ, Hruska KA: BMP-7 is an efficacious treatment of vascular calcification in a murine model of atherosclerosis and chronic renal failure. J Am Soc Nephrol 2003; 14:1559-1567.

Demer LL, Tintut Y, Parhami F: Novel mechanisms in accelerated vascular calcification in renal disease patients. Curr Opin Nephrol Hypertens 2002;11:437-443.

Deppisch RM, Beck W, Goehl H, et al: Complement components as uremic toxins and their potential role as mediators of microinflammation. Kidney Int Suppl 2001;78:S271-S277.

Descamps-Latscha B, Witko-Sarsat V, NguyenKhoa T, Nguyen AT, Gausson V, Mothu N, London GM, Jungers P: Advanced oxidation protein products as risk factors for atherosclerotic cardiovascular events in nondiabetic predialysis patients. Am J Kidney Dis 2005;45: 39-47.

Fliser D, Pacini G, Engelleiter R, Kautzky-Willer A, Prager R, Franek E, Ritz E: Insulin resistance and hyperinsulinemia are already present in patients with incipient renal disease. Kidney Int 1998;53:1343-1347.

Ganesh SK, Stack AG, Levin NW, HulbertShearon T, Port FK: Association of elevated serum $\mathrm{PO}(4), \mathrm{Ca} \times \mathrm{PO}(4)$ product, and parathyroid hormone with cardiac mortality risk in chronic hemodialysis patients. J Am Soc Nephrol 2001;12:2131-2138.
Goodman WG, Goldin J, Kuizon BD, et al: Coronary-artery calcification in young adults with end-stage renal disease who are undergoing dialysis. N Engl J Med 2000;342:1478-1483.

Goodman WG, London G, Amann K, Block GA, Giachelli C, Hruska KA, Ketteler M, Levin A, Massy Z, McCarron DA, Raggi P, Shanahan CM, Yorioka N, Vascular Calcification Work Group: Vascular calcification in chronic kidney disease. Am J Kidney Dis 2004;43:572579.

Harnett JD, Foley RN, Kent GM, Barre PE, Murray DC, Parfrey PS: Congestive heart failure in dialysis patients: prevalence, incidence, prognosis, and risk factors. Kidney Int 1996;49: 1428-1434.

Hosokawa K, Kuriyama S, Astumi Y, Kaneda S, Mastuoka K: Incidence of peripheral arteriosclerotic complications of the lower extremities in diabetic patients with chronic renal failure. Ther Apher Dial 2005;9:161-166.

Huang H, Virmani R, Younis H, et al: The impact of calcification on the biomechanical stability of atherosclerotic plaques. Circulation 2001; 103:1051-1056.

Huybrechts KF, Caro JJ, London GM: Modeling the implications of changes in vascular calcification in patients on hemodialysis. Kidney Int 2005; 67:1532-1538.

Ibels LS, Alfrey AC, Huffer WE, Crashwell PW, Anderson JT, Weil R: Arterial calcification and pathology in uremic patients undergoing dialysis. Am J Med 1979;66:790-796.

Ikram H, Lynn KL, Bailey RB, Little PJ: Cardiovascular changes in chronic hemodialysis patients. Kidney Int 1983;24:371-376.

Ivanovski O, Szumilak D, Nguyen-Khoa T, Ruellan N, Phan O, Lacour B, Descamps-Latscha B, Drueke TB, Massy ZA: The antioxidant Nacetylcysteine prevents accelerated atherosclerosis in uremic apolipoprotein $\mathrm{E}$ knockout mice. Kidney Int 2005;67:2288-2294.

Jono S, McKee MD, Murry CE, et al: Phosphate regulation of vascular smooth muscle cell calcification. Circ Res 2000;87:E10-E17.

Jungers P, Joly D, Massy Z, Chauveau P, Nguyen AT, Aupetit J, Chadefaux B: Sustained reduction of hyperhomocysteinaemia with folic acid supplementation in predialysis patients. Nephrol Dial Transplant 1999;14:2903-2906.

Ketteler M, Gross ML, Ritz E: Calcification and cardiovascular problems in renal failure. Kidney Int Suppl 2005;94:s120-s127.

Kielstein JT, Boger RH, Bode-Boger SM, Frolich JC, Haller H, Ritz E, Fliser D: Marked increase of asymmetric dimethylarginine in patients with incipient primary chronic renal disease. $\mathrm{J}$ Am Soc Nephrol 2002;13:170-176.

Kramer W, Wizemann V, Thormann J, Kindler M, Mueller K, Schlepper M: Cardiac dysfunction in patients on maintenance hemodialysis. I. The importance of associated heart diseases in determining alterations of cardiac performance. Contrib Nephrol. Basel, Karger, 1986 , vol 52, pp 97-109. 
Kronenberg F, Kuen E, Ritz E, Konig P, Kraatz G, Lhotta K, Mann JF, Muller GA, Neyer U, Riegel W, Riegler P, Schwenger V, von Eckardstein A: Apolipoprotein A-IV serum concentrations are elevated in patients with mild and moderate renal failure. J Am Soc Nephrol 2002;13:461-469.

Kronenberg F, Kuen E, Ritz E, Junker R, Konig P, Kraatz G, Lhotta K, Mann JF, Muller GA, Neyer U, Riegel W, Reigler P, Schwenger V, Von Eckardstein A: Lipoprotein(a) serum concentrations and apolipoprotein(a) phenotypes in mild and moderate renal failure. J Am Soc Nephrol 2000;11:105-115.

Leskinen Y, Salenius JP, Lehtimaki T, Huhtala H, Saha $\mathrm{H}$ : The prevalence of peripheral arterial disease and medial arterial calcification in patients with chronic renal failure: requirements for diagnostics. Am J Kidney Dis 2002;40: 472-479.

Lindner A, Charra B, Sherrard DJ, Scribner BH: Accelerated atherosclerosis in prolonged maintenance hemodialysis. N Engl J Med 1974;290: 697-701.

London GM: Cardiovascular calcifications in uremic patients: clinical impact on cardiovascular function. J Am Soc Nephrol. 2003;14(9 suppl 4):S305-S309.

London GM, Marty C, Marchais SJ, Guerin AP, Metivier F, de Vernejoul MC: Arterial calcifications and bone histomorphometry in endstage renal disease. J Am Soc Nephrol 2004; 15 : 1943-1951.

Moe SM, O’Neill KD, Duan D, et al: Medial artery calcification in ESRD patients is associated with deposition of bone matrix proteins. Kidney Int 2002;61:638-647.

Moe SM, Chen NX: Inflammation and vascular calcification. Blood Purif 2005;23:64-71.

Moe SM, Reslerova M, Ketteler M, O'Neill K, Duan D, Koczman J, Westenfeld R, JahnenDechent W, Chen NX: Role of calcification inhibitors in the pathogenesis of vascular calcification in chronic kidney disease (CKD). Kidney Int 2005;67:2295-2304.

Muntzel M, Massy Z, Ruellan N, et al: Chronic renal failure increase oxidative stress and accelerates atherosclerosis in apolipoprotein-E knock-out mice. Nephrol Dial Transpl 2002; 17(suppl 1):46a.

Narang R, Ridout D, Nonis C, Kooner JS: Serum calcium, phosphorus and albumin levels in relation to the angiographic severity of coronary artery disease. Int J Cardiol 1997;60:73-79.

Neves KR, Graciolli FG, dos Reis LM, Pasqualucci CA, Moyses RM, Jorgetti V: Adverse effects of hyperphosphatemia on myocardial hypertrophy, renal function, and bone in rats with renal failure. Kidney Int 2004;66:22372244.

Oh J, Wunsch R, Turzer M, et al: Advanced coronary and carotid arteriopathy in young adults with childhood-onset chronic renal failure. Circulation 2002;106:100-105.

O'Hare AM, Hsu CY, Bacchetti P, Johansen KL: Peripheral vascular disease risk factors among patients undergoing hemodialysis. J Am Soc Nephrol 2002;13:497-503.
O'Hare AM, Bertenthal D, Shlipak MG, Sen S, Chren MM: Impact of renal insufficiency on mortality in advanced lower extremity peripheral arterial disease. J Am Soc Nephrol 2005; 16:514-519. Epub 2004 Dec 15.

Pannier B, Guerin AP, Marchais SJ, Safar ME, London GM: Stiffness of capacitive and conduit arteries: Prognostic significance for endstage renal disease patients. Hypertension 2005;45:592-596.

Park L, Raman KG, Lee KJ, et al: Suppression of accelerated diabetic atherosclerosis by the soluble receptor for advanced glycation endproducts. Nat Med 1998;9:1025-1031.

Raggi P, Boulay A, Chasan-Taber S, et al: Cardiac calcification in adult hemodialysis patients: a link between end-stage renal disease and cardiovascular disease? J Am Coll Cardiol 2002; 39:695-701.

Richardson PD, Davies MJ, Born GV: Influence of plaque configuration and stress distribution on fissuring of coronary atherosclerotic plaques. Lancet 1989;ii:941-944.

Ridker PM, Hennekens CH, Buring JE, Rifai N: $\mathrm{C}$-reactive protein and other markers of inflammation in the prediction of cardiovascular disease in women. N Engl J Med 2000;342: 836-843.

Scalera F, Kielstein JT, Martens-Lobenhoffer J, Postel SC, Tager M, Bode-Boger SM: Erythropoietin increases asymmetric dimethylarginine in endothelial cells: role of dimethylarginine dimethylaminohydrolase. J Am Soc Nephrol 2005;16:892-898. Epub 2005 Feb 23.

Schieffer B, Schieffer E, Hilfiker-Kleiner D, et al: Expression of angiotensin II and interleukin 6 in human coronary atherosclerotic plaques: potential implications for inflammation and plaque instability. Circulation 2000;101:1372_ 1378 .

Schmermund A, Baumgart D, Erbel R: Coronary heart disease risk in patients without angina pectoris: coronary calcinosis as a prognostic factor for myocardial infarct? MMW Fortschr Med 2001;143:27-29.

Schwarz U, Buzello M, Ritz E, et al: Morphology of coronary atherosclerotic lesions in patients with end-stage renal failure. Nephrol Dial Transplant 2000;15:218-223.

Schwedler SB, Amann K, Wernicke K, Krebs A, Nauck M, Wanner C, Potempa LA, Galle J: Native C-reactive protein increases, whereas modified C-reactive protein reduces atherosclerosis in apolipoprotein E-knockout mice. Circulation 2005;112:1016-1023.

Siems W, Quast S, Carluccio F, Wiswedel I, Hirsch D, Augustin W, Hampl H, Riehle M, Sommerburg O: Oxidative stress in chronic renal failure as a cardiovascular risk factor. Clin Nephrol 2002;58(suppl 1-2002):S12-S19.

Siems WG, Sommerburg O, Grune T: Erythrocyte free radical and energy metabolism. Clin Nephrol 2000;53(suppl 1-2000):S9-S17.

Shoji T, Emoto M, Tabata T, et al: Advanced atherosclerosis in predialysis patients with chronic renal failure. Kidney Int 2002;61:2187-2192.

Stary HC, Chandler AB, Dinsmore RE, Fuster V, Glagov S, Insull W Jr, Rosenfeld ME, Schwartz
CJ, Wagner WD, Wissler RW: A definition of advanced types of atherosclerotic lesions and a histological classification of atherosclerosis. A report from the Committee on Vascular Lesions of the Council on Arteriosclerosis, American Heart Association. Arterioscler Thromb Vasc Biol 1995; 15:1512-1531.

Stefanski A, Schmidt KG, Waldherr R, Ritz E: Early increase in blood pressure and diastolic left ventricular malfunction in patients with glomerulonephritis. Kidney Int 1996;50:13211326.

Stenvinkel P, Heimburger O, Paultre F, et al: Strong association between malnutrition, inflammation, and atherosclerosis in chronic renal failure. Kidney Int 1999;55:1899-1911.

Torzewski J, Torzewski M, Bowyer DE, et al: Creactive protein frequently colocalizes with the terminal complement complex in the intima of early atherosclerotic lesions of human coronary arteries. Arterioscler Thromb Vasc Biol 1998; 18:1386-1392.

Touyz RM, Schiffrin EL: Increased generation of superoxide by angiotensin II in smooth muscle cells from resistance arteries of hypertensive patients: role of phospholipase D-dependent NAD(P)H oxidase-sensitive pathways. J Hypertens 2001;19:1245-1254.

Touyz RM: Intracellular mechanisms involved in vascular remodeling of resistance arteries in hypertension: role of angiotensin II. Exp Physiol 2005. Epub ahead of print.

Tvedegaard E, Kamstrup O: The effect of chronic renal failure in rabbits on plasma lipids and the concentration of cholesterol, calcium and phosphate in the aortic wall. Proc Eur Dial Transplant Assoc 1980;17:240-246.

US Renal Data System: Causes of death. Annual Data Report. Bethesda, National Institute of Health, National Institute of Diabetes and Digestive and Kidney Diseases, 1995, vol 14, pp 79-90.

Valkonen VP, Paiva H, Salonen JT, Lakka TA, Lehtimaki T, Laakso J, Laaksonen R: Risk of acute coronary events and serum concentration of asymmetrical dimethylarginine. Lancet 2001;358:2127-2128.

Witko-Sarsat V, Friedlander M, Nguyen Khoa T, et al: Advanced oxidation protein products as novel mediators of inflammation and monocyte activation in chronic renal failure. J Immunol 1998;161:2524-2532.

Yusuf S, Sleight P, Pogue J, et al: Effects of an angiotensin-converting-enzyme inhibitor, ramipril, on cardiovascular events in high-risk patients. The Heart Outcomes Prev Eval Study Investigators. N Engl J Med 2000;342:145153

Zimmermann J, Herrlinger S, Pruy A, Metzger T, Wanner C: Inflammation enhances cardiovascular risk and mortality in hemodialysis patients. Kidney Int 1999;55:648-658.

Zoccali C, Benedetto FA, Maas R, Mallamaci F, Tripepi G, Malatino LS, Boger R, CREED Investigators: Asymmetric dimethylarginine, Creactive protein, and carotid intima-media thickness in end-stage renal disease. J Am Soc Nephrol 2002;13:490-496. 